\title{
The Primary Structure of Aspartate Aminotransferase from Pig Heart Muscle
}

\section{PARTIAL SEQUENCES DETERMINED BY DIGESTION WITH THERMOLYSIN AND ELASTASE}

\author{
By FRANCESCO BOSSA, DONATELLA BARRA, MASSIMO CARLONI, \\ PAOLO FASELLA and FRANCESCA RIVA \\ Istituto di Chimica Biologica e Centro di Biologia Molecolare del Consiglio Nazionale delle Ricerche, \\ Università di Roma, Città Universitaria, 00185 Roma, Italy \\ and SHAWN DOONAN, HILARY J. DOONAN, ROBIN HANFORD, \\ CHARLES A. VERNON and JOHN M. WALKER \\ Department of Chemistry, University College London, 20 Gordon Street, London WC1H 0AJ, U.K.
}

(Received 22 February 1973)

\begin{abstract}
Peptides produced by thermolytic digestion of aminoethylated aspartate aminotransferase and of the oxidized enzyme were isolated and their amino acid sequences determined. Digestion by elastase of the carboxymethylated enzyme gave peptides representing approximately $40 \%$ of the primary structure. Fragments from these digests overlapped with previously reported sequences of peptides obtained by peptic and tryptic digestion (Doonan et al., 1972), giving ten composite peptides containing 395 amino acid residues. The amino acid composition of these composite peptides agrees well with that of the intact enzyme. Confirmatory results for some of the present data have been deposited as Supplementary Publication 50018 at the National Lending Library for Science and Technology, Boston Spa, Yorks. LS23 7BQ, U.K., from whom copies can be obtained on the terms indicated in Biochem. J. (1973) 131, 5.
\end{abstract}

The determination of the primary structure of the soluble (cytoplasmic) form of aspartate aminotransferase (L-aspartate-2-oxoglutarate aminotransferase, EC 2.6.1.1) from pig heart muscle has been undertaken and the results of digestion of the enzyme with trypsin and pepsin have been published (Doonan et al., 1972). Overlapping of fragments from the peptic and tryptic digests gave 20 composite peptides containing 260 amino acid residues; in addition, there remained a further 20 peptides containing approximately 140 amino acid residues that could not be placed in the partial primary sequence reported. Similar results were obtained by Ovchinnikov et al. (1971).

To obtain overlapping fragments, digests were done with thermolysin and elastase. Thermolysin was chosen because it digested aspartate aminotransferase to a completely soluble mixture of peptides. Thermolysin cleaved the protein fairly specifically $N$-terminal to long-chain aliphatic amino acids and to phenylalanine (Matsubara, 1970), thus supplying useful overlaps with peptides obtained by tryptic and peptic digestion. The digestion with elastase was used because the specificity of elastase, although rather general (Shotton, 1970), was complementary to that of the other proteolytic enzymes employed.

Work has also been carried out with chymotrypsin, in the hope of obtaining information not yielded by the peptic digest due to the somewhat low specificity of pepsin, and with $\mathrm{CNBr}$. The full details and results of these digests are not included in the present paper, which lists only those peptides that are of particular interest.

\section{Experimental}

Details of the following experimental methods are given in the previous paper [Doonan et al. (1972) and Supplementary Publication SUP 50011]: modification of the enzyme by carboxymethylation and aminoethylation; purification of peptides by gel filtration through Sephadex G-25 and G-50; ionexchange chromatography on Bio-Rad AG-50W-X2 resin; paper chromatography and high-voltage electrophoresis at $\mathrm{pH} 3.5$ and 6.5; determination of amino acid compositions of peptides; digestion of peptides with carboxypeptidases; $\boldsymbol{N}$-terminal analysis and amino acid sequence determinations.

\section{Materials}

Aspartate aminotransferase used for digestion with thermolysin was prepared by the method of MartinezCarrion et al. (1967). The enzyme used for digestion 
with elastase was purchased from Whatman Biochemicals Ltd., Maidstone, Kent, U.K.; this material is prepared essentially as described by Banks et al. (1968).

\section{Modification and proteolytic digestion of aspartate aminotransferase}

Aminoethylation (Cole, 1967) and carboxymethylation (Crestfield et al., 1963) of the apoenzyme were carried out as described in Supplementary Publication SUP 50011. Performic acid oxidation of the holoenzyme was carried out by the method of Hirs (1956).

For the prolonged thermolytic digestion, $\mathrm{H}_{2} \mathrm{NEt}$ Enzyme* $\left(480 \mathrm{mg}\right.$ ) was suspended in $\mathrm{NH}_{4} \mathrm{HCO}_{3}$ $(0.1 \mathrm{M} ; 70 \mathrm{ml})$ and incubated at $37^{\circ} \mathrm{C}$ with thermolysin (Merck, Darmstadt, Germany) $(5 \mathrm{mg})$ dissolved in $2.5 \mathrm{~mm}-\mathrm{CaCl}_{2}(5 \mathrm{ml})$. After $2 \mathrm{~h}$ a second portion of thermolysin $(2.5 \mathrm{mg})$ was added. The oxidized holoenzyme $(460 \mathrm{mg}$ ) was digested in the same way except that no second addition of thermolysin was made. For the limited digestion, $\mathrm{H}_{2} \mathrm{NEt}$-Enzyme $(630 \mathrm{mg})$ was suspended in $1 \mathrm{mM}-\mathrm{CaCl}_{2}(50 \mathrm{ml})$ with vigorous stirring and incubated at $40^{\circ} \mathrm{C}$ with thermolysin $(4 \mathrm{mg})$. The $\mathrm{pH}$ was maintained at 8.0 by titration with $0.2 \mathrm{M}-\mathrm{NaOH}$ in a pH-stat (Radiometer TTT1c) and the reaction was stopped by acidification of the mixture when the equivalent of 20 peptide bonds had been broken as judged by the consumption of $\mathrm{NaOH}$. Cm-Enzyme $(400 \mathrm{mg})$ was suspended in water $(40 \mathrm{ml})$, titrated to $\mathrm{pH} 8.0$ with $0.16 \mathrm{M}-\mathrm{NH}_{3}$ and incubated at $37^{\circ} \mathrm{C}$ with elastase (Whatman Biochemicals Ltd., Maidstone, Kent, U.K.) (0.8 mg). The pH was maintained at 8.0 by titration with $0.16 \mathrm{M}$ $\mathrm{NH}_{3}$ and the reaction was stopped by acidification when the equivalent of 40 peptide bonds had been broken.

\section{Peptide separation}

Peptide mixtures from the thermolytic digests were subjected to preliminary fractionation by gel filtration through Sephadex G-25, followed by Sephadex G-50. The fractions obtained were purified by ion-exchange chromatography on Bio-Rad AG-50W-X2 as described in Supplementary Publication SUP 50011. For the separation of peptides from the limited thermolytic digest, SP-Sephadex C-25 was substituted for the polystyrene resin and a more acidic gradient produced by including a pyridine $(0.2 \mathrm{M})$-formate buffer, $\mathrm{pH} 2.7$, in addition to those at $\mathrm{pH} 3.1,5.1$ and 6.5. In some cases this purification step was followed

${ }^{*}$ Abbreviations: $\mathrm{Cm}$-Enzyme and $\mathrm{H}_{2} \mathrm{NEt}$-Enzyme, carboxymethylated and aminoethylated aspartate aminotransferase respectively; $\operatorname{Met}\left(\mathrm{O}_{2}\right), \mathrm{CmCys}, \mathrm{Cys}\left(\mathrm{O}_{3} \mathrm{H}\right)$ and $\mathrm{H}_{2} \mathrm{NEtCys}$ (in sequences), methionine sulphone, carboxymethylcysteine, cysteic acid and aminoethylcysteine respectively. by further ion-exchange chromatography on a Chromobead P-4 (Technicon) column $(0.9 \mathrm{~cm} \times 15 \mathrm{~cm})$ in the same buffer system. Other techniques used for peptides that required further purification were paper chromatography (Waley \& Watson, 1953) and highvoltage paper electrophoresis, in a liquid-cooled tank system, at pH1.9 (formic acid-acetic acidwater, $1: 4: 45$, by vol.). The peptide mixture from the digestion with elastase was fractionated by passage through Sephadex G-25 and the fractions obtained were purified by a combination of paper chromatography and high-voltage paper electrophoresis at pH5.3 and 6.5.

\section{$N$-Terminal analysis and amino acid analysis}

The purity of peptides was established by the dansylation technique of Gray (1967). The previously described technique of complete dansylation of hydrolysates (Doonan et al., 1972) was used to obtain qualitative amino acid analyses of peptides from the digestion with elastase. Quantitative amino acid analyses were carried out on the thermolytic peptides and the results are given in the Supplementary Publication (SUP 50018).

\section{Amino acid sequence determinations}

The amino acid sequences of peptides were determined by the dansyl-Edman technique described by Hartley (1970). In the case of some thermolytic peptides where an aspartate/asparagine or glutamate/ glutamine residue occurred at the $C$-terminus, the appropriate number of Edman cycles were performed after which the liberated $C$-terminal amino acid was identified by amino acid analysis. Alternatively, the states of amidation were assigned by hydrolysis of the peptide with aminopeptidase (Light, 1972) followed by amino acid analysis. The $C$-terminal sequences of some thermolytic peptides were confirmed by hydrolysis with carboxypeptidases A, B and C (Ambler, 1967, 1972). Details and results of aminopeptidase and carboxypeptidase digestions are given in the Supplementary Publication (SUP 50018).

\section{Results}

Peptides from the prolonged thermolytic digest of aminoethylated aspartate aminotransferase

The 45 peptides were isolated in yields ranging from $1-51 \%$. The amino acid sequences are shown in Fig. 1, the peptides being labelled TL-1-TL-45 in order of increasing size. The states of amidation were assigned either as described in the preceding section and are as indicated in Fig. 1, or from information obtained from tryptic and peptic peptides (Doonan et al., 1972). The sequence of the $C$-terminal portion of peptide TL-45 was established by comparison with peptide TLS-18 from the limited thermolytic digest. 


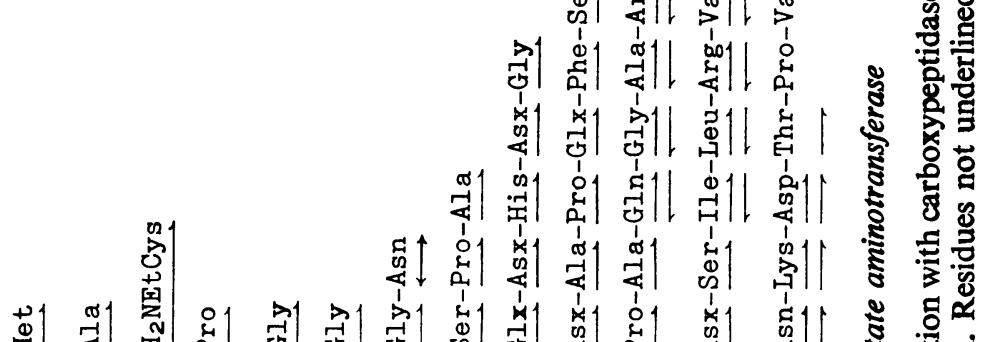

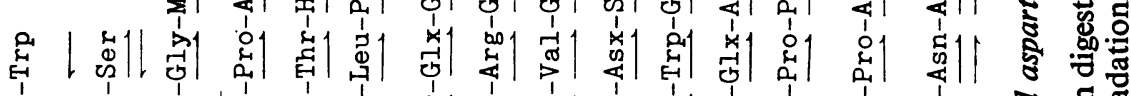

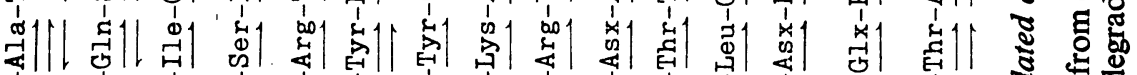

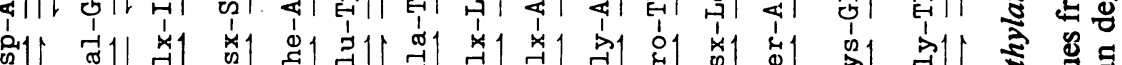

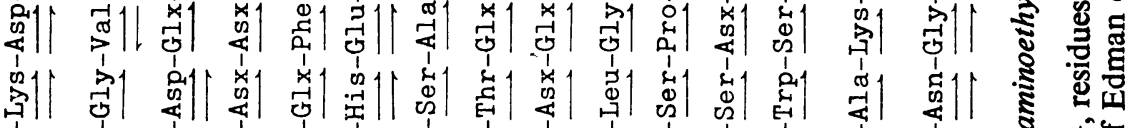

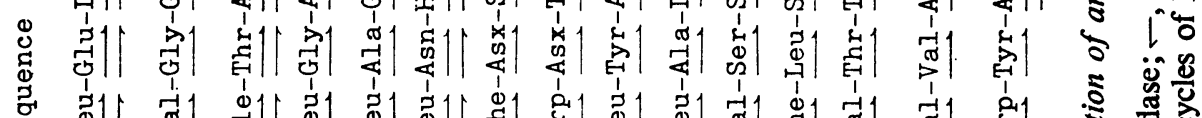

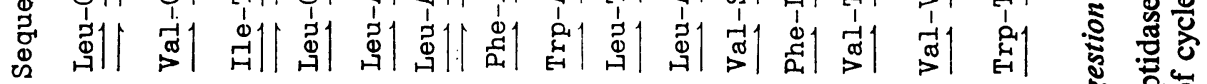

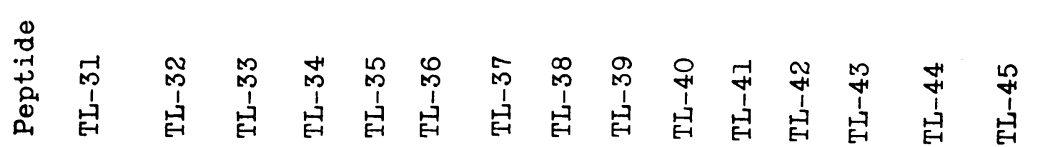

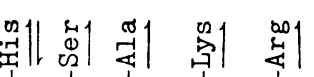

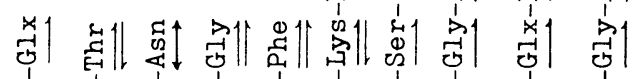

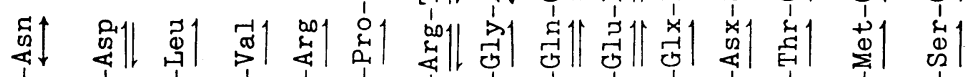

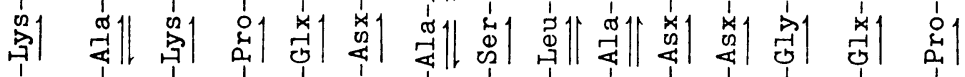

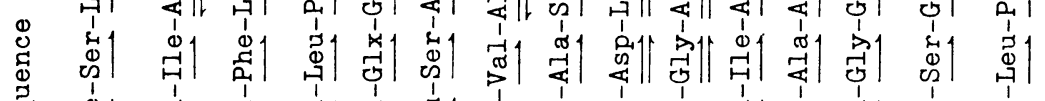

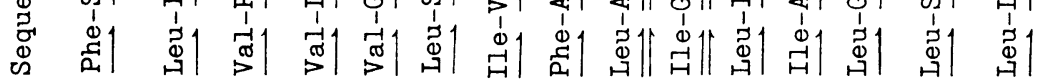

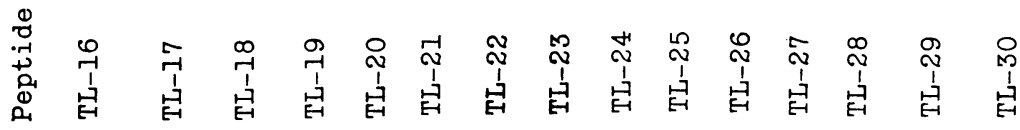
ช จั ส

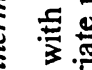

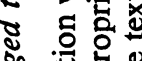

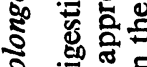
궁 ฟ 5

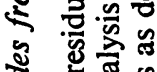
: ¿ें

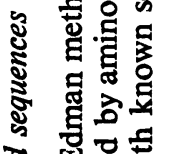

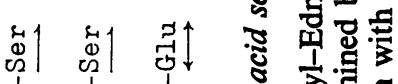

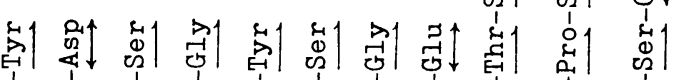

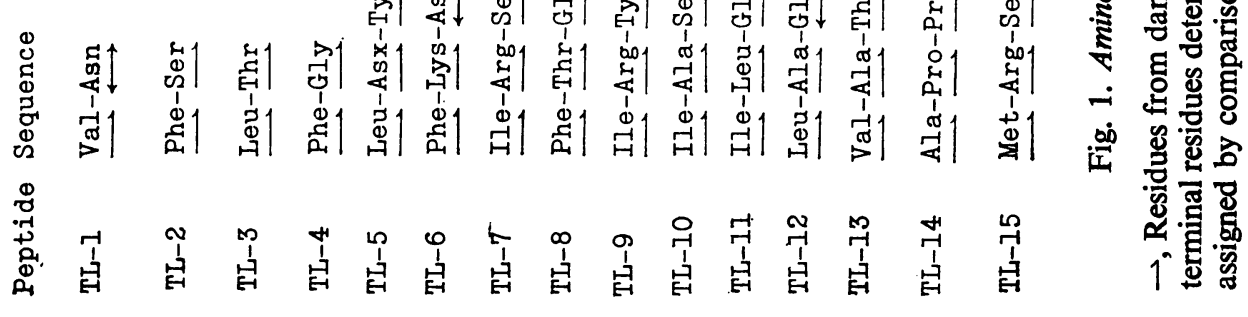
Vol. 133 


\section{Peptides from the thermolytic digest of oxidized aspartate aminotransferase}

The amino acid sequences of ten peptides (TLO-1 TLO-10) that were isolated after digestion of the oxidized enzyme but were not found in the prolonged thermolytic digest, and which contained five oxidized cysteine residues, are shown in Fig. 2. The sequence of the $C$-terminal portion of peptide TLO-10 was established by comparison with the peptide TLS-17.

\section{Peptides from the limited thermolytic digest of amino- ethylated aspartate aminotransferase}

A further 19 peptides (TLS-1-TLS-19) were isolated from this digest and the sequences are shown in Fig. 3. Where these peptides were composed, in part, of one or more peptides obtained from the other thermolytic digests, the numbers of the corresponding shorter peptides are given in parentheses. The sequence of the $C$-terminal part of peptide TLS-12 was inferred from the sequence of peptide TL-38 and the sequences of the $C$-terminal parts of peptides TLS-16 and TLS-19 were deduced by comparison with composite peptides III and XI from the results with trypsin and pepsin digests (Doonan et al., 1972). The agreement between the sequence and amino acid analysis of peptide TLS-16 (Table 2) was less close than usual, particularly with respect to glutamic acid. The correctness of the sequence of peptide TLS-16 was confirmed by comparison with peptides TL-19, TLO-7, E-15, E-16 and E-16'; hence it seems likely that peptide TLS-16 contained impurities that resulted in a poor amino acid analysis but which did not affect the sequence determination.

\section{Peptides from the digestion of carboxymethylated aspartate aminotransferase with elastase}

The partial and complete amino acid sequences of peptides obtained from the digestion with elastase are shown in Fig. 4; five dipeptides that were isolated and sequenced have not been included. The peptides listed in Fig. 4 were not subjected to quantitative amino acid analysis because of lack of material, but qualitative amino acid analyses by complete dansylation of hydrolysates (see the Experimental section) were consistent with the sequences reported here. The sequence data were unambiguous in all cases.

Peptides E-15 and E-16 originated from acid cleavage between aspartate and proline residues at their $C$ - and $N$-termini respectively during gel filtration of the original peptide mixture at low $\mathrm{pH}$. Peptide E-16' had not undergone this cleavage at the aspartic acid-proline bond although the bonds cleaved by elastase at both the $N$ - and $C$-termini differ from those in peptides E-15 and E-16. Peptide E-20 appeared to be blocked at the $N$-terminus and was not degraded by the Edman procedure. It was therefore digested with trypsin and the liberated peptides were partially sequenced; the central portion of the peptide was assigned by comparison with composite peptide XIII from the trypsin and pepsin digests. Peptide E-21 was sequenced only as far as residue 18; there was insufficient material for quantitative amino acid analysis of the peptide.

\section{Additional peptides obtained from chymotryptic tryptic and peptic digests}

The sequences of a small number of peptides from the chymotryptic digest of carboxymethylated aspartate aminotransferase are listed in Fig. 5 (CH-1-CH-7) (D. Barra, F. Bossa \& F. Riva, unpublished work). Also included in Fig. 5 are the sequences of two previously unreported peptides from the tryptic digest of $\mathrm{H}_{2} \mathrm{NEt}$-Enzyme (TAE-18 and TAE-19). Peptide RP-1 was obtained from a restricted digest of $\mathrm{Cm}$-Enzyme with pepsin. Confirmatory evidence for these sequences is presented in the Supplementary Publication (SUP 50018).

Fragment obtained from cleavage of the carboxymethylated enzyme with $\mathrm{CNBr}$

A fragment containing 72 amino acid residues was isolated from the Cm-Enzyme after cleavage with $\mathrm{CNBr}$ (R. Hanford, unpublished work). The purified fragment was further digested with trypsin, then the resulting peptides were isolated and their sequences determined (Supplementary Publication SUP 50018). The tryptic peptides contained the following amino acid residues (numbering system from Fig. 6): 49-54, 56-59, 60-80, 86-98, 100-113 and 114-121. In addition, free lysine and arginine were found, presumably originating from positions 55 and 99 respectively. The peptide Thr-Cys-Ala-Ser-Arg (residues 81-85) could not be isolated from the tryptic digest, although dansylation of the digest before fractionation showed the presence of a peptide with $N$-terminal threonine. These data have been used to establish the junction between the two sections (1-85 and 86-153) of fragment $\mathrm{A}$ in Fig. 6. It is interesting that the $\mathrm{CNBr}$ fragment originated from cleavage at tryptophan at both ends (positions 48 and 122); this was presumably caused by the presence of free bromine in the commercial sample of $\mathrm{CNBr}$ used (Koch-Light Laboratories Ltd., Colnbrook, Bucks., U.K.).

\section{Discussion}

From the amino acid sequences of the peptides obtained by digestion of aspartate aminotransferase with trypsin, pepsin, thermolysin, elastase, chymotrypsin and by cleavage with $\mathrm{CNBr}$ the sequences of ten composite fragments containing 395 amino acid residues were deduced. These are shown labelled $A$ to $\mathrm{J}$ in Fig. 6. The Roman numerals in Fig. 6 refer to 


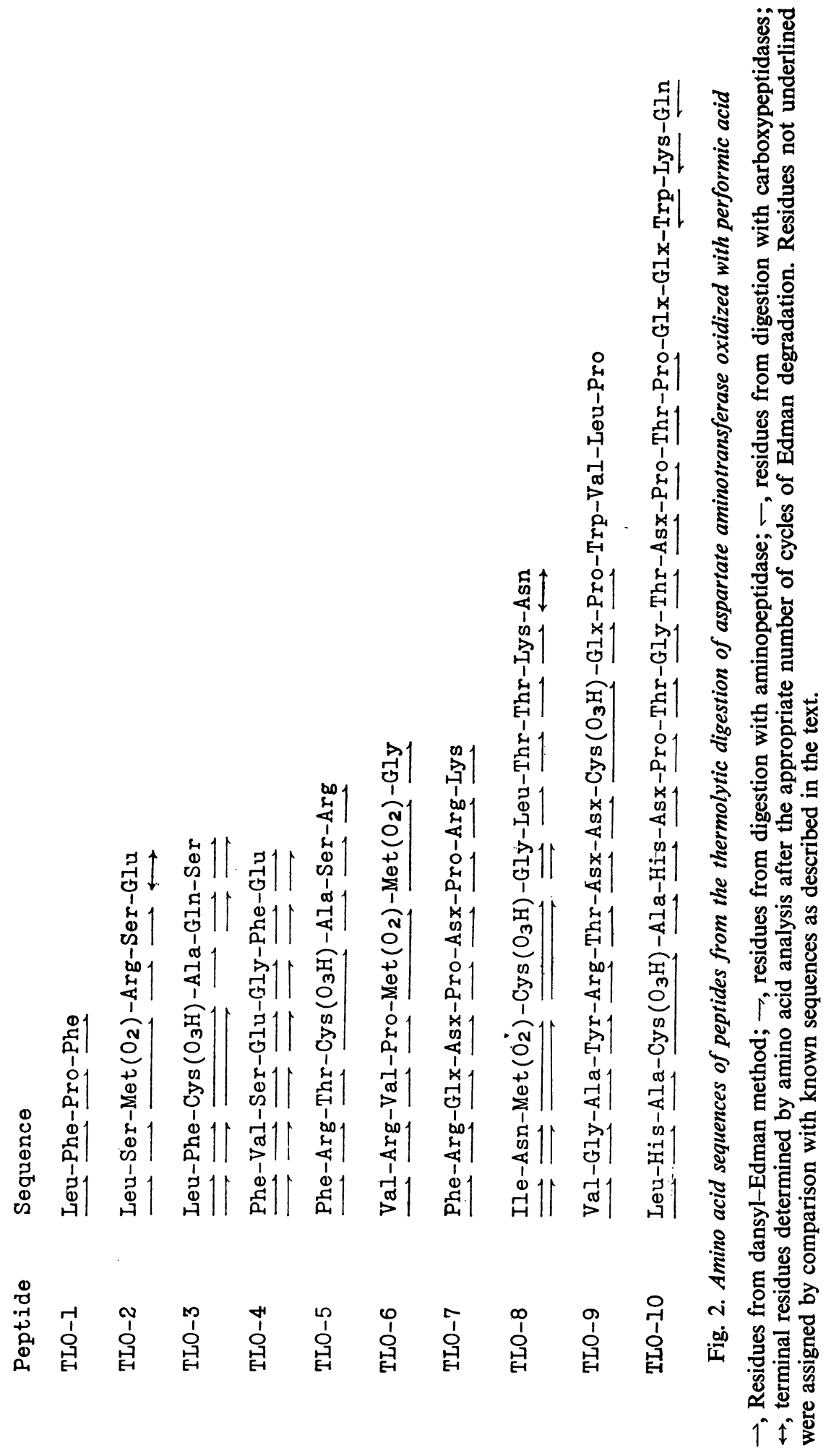

Vol. 133 
罂

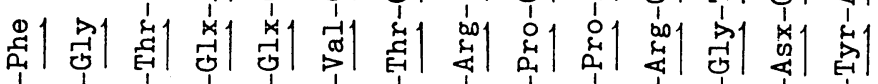

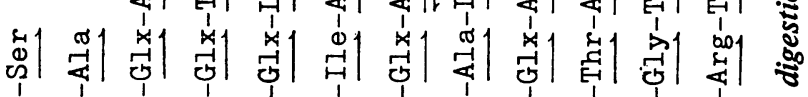

疍

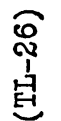

龺

$+$

官

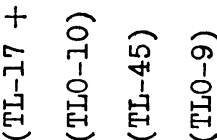

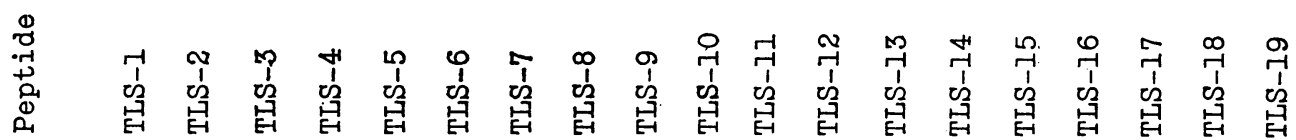

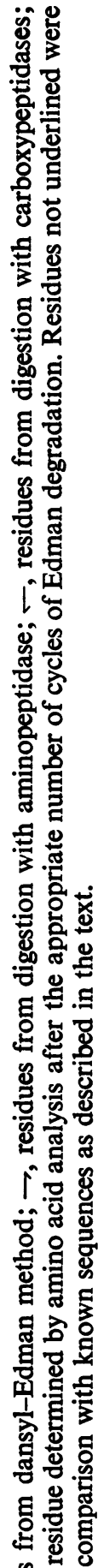


composite tryptic/peptic fragments and the symbols TAE, TM and $P$ refer to peptides produced by digestion of the modified enzyme with trypsin and pepsin respectively (Doonan et al., 1972). The largest of the composite fragments is the $N$-terminal sequence of 153 amino acid residues. The evidence for the overlap between residues 85 and 86 of this fragment has been discussed in the previous section. It seems likely from the results given in Fig. 6 that there are direct overlaps between fragments $A$ and $B, E, F$ and $G$ and $\mathrm{I}$ and $\mathrm{J}$ but further evidence is required to establish these overlaps with certainty.

All of the tryptic peptides and most of the peptic peptides previously reported have been positioned in fragments A to J. Of the peptides in Figs. 1-4 of the present work, only four (TL-2, TL-9, TL-33 and TLO-6) have not been placed in the composite fragments. Peptide TL-2 is probably part of the peptic peptide (P10-j) Phe-Ser-Phe and peptide TL-9 is part of peptide P8-16, Ala-Ile-Arg-Tyr. The three peptides, P10-3, P8-16 and TL-33 must be included in the primary structure to give a total of 406 amino acid residues. Table 1 shows the amino acid composition of aspartate aminotransferase as determined separately in our laboratories (Banks et al., 1968; Martinez-Carrion et al., 1967) and the total amino acid content of fragments $A$ to $J$ plus peptides TL-33, P10-3 and P8-16. It can be seen that the values are in good agreement. There remain a few peptic peptides, containing a total of ten amino acid residues, which have not been included in the composite fragments or the amino acid composition in Table 1. These peptides were obtained in very low yields and were found in none of the other digests performed, and their sequences must, therefore, be considered doubtful. Peptide TLO-6 has also been excluded from the amino acid composition and from Fig. 6. This peptide (amino acid composition in Table 2) contains two methionine residues, the inclusion of which would increase the total found to eight instead of the six required by the amino acid composition of the intact molecule. The peptide was isolated in very low yield $(1 \%)$, which suggests that it arose from a contaminating protein. If peptide TLO-6 is part of the primary sequence of aspartate aminotransferase then it must be fitted to the $C$ terminus of fragment $\mathrm{G}$. $\mathrm{CNBr}$ cleavage should then result in the formation of the eight-residue peptide Glx-Lys-Ile-Val-Arg-Val-Pro-Hse; this peptide has not yet been found in a digest of the enzyme with CNBr. The sequence of peptide TLO-6 (Fig. 2) is open to question. The amino acid composition shown in Table 2 suggests that the peptide contained a further glycine residue and a serine residue at the $C$-terminus, but these were not observed during sequence analysis. It is possible that the high glycine and serine content arose from the presence of an impurity in the peptide.
Three discrepancies have been observed between the results given here and those previously published (Doonan et al., 1972). Peptide TAE-12', the complete sequence of which was not established, was thought to contain four residues of threonine whereas the correct number is five. This peptide contains the three thermolytic peptides TL-45, TL-41 and TLS-7; the total content of threonine in these peptides is five residues (Table 2). The $N$-terminal residue of peptide P8-8 has now been reassigned as leucine by comparison with the $N$-terminal residue of peptide TLS-8 (Fig. 3 and Table 2); peptide P8-8 was a minor component in the peptic digest and was obtained in very low yield, thus giving difficulties in sequence analysis. The $C$-terminal residue of fragment $\mathrm{V}$ was shown to be valine by comparison with the $C$-terminal residue of peptide TL-44 (Fig. 1 and Table 2); the nature of this residue has now been confirmed by digestion of peptide TL-44 with carboxypeptidase (Supplementary Publication 50018). Similarly, at two positions (residue 10 of fragment $X$ and residue 6 of peptide TAE-12') we originally suggested double assignments. In the present work, only proline was found at the position corresponding to residue 10 of fragment $X$ (residue 8 of peptide E-14; Fig. 4) and only asparagine at the position equivalent to residue 6 of TAE-12' (residue 6 of peptide TL-45; Fig. 3, Table 2). In the absence of further evidence to the contrary we have assigned proline and asparagine as the correct residues at these positions (Fig. 6).

While this paper was in preparation the Russian group (Ovchinnikov et al., 1973) proposed a primary structure for aspartate aminotransferase. No indication was given of the information used to deduce the structure from their previously published sequences of 21 fragments (Ovchinnikov et al., 1971) and it is, therefore, difficult to assess the reliability of the structure they proposed. The results presented by the Russian authors are generally in agreement with those given in Fig. 6. Note, however, that they proposed a direct overlap between sequences corresponding to our fragments $\mathrm{G}$ and $\mathrm{H}$, which would require that peptide TLO-6 is not part of the structure of aspartate aminotransferase (see above). It would be interesting to see the evidence from which they deduced the proposed structure of this part of the molecule.

We found that the thermolysin digestions of aspartate aminotransferase were the most successful, in that a total of 375 amino acid residues were identified (Figs. 1-3). The cleavage was relatively specific. All but five of the 74 thermolytic peptides presented here have leucine, isoleucine, phenylalanine or valine at their $N$-termini; the five exceptions have tryptophan (2), methionine (1), tyrosine (1) or alanine (1) (frequency in parentheses). In the prolonged digestion with thermolysin, cleavage at leucine, isoleucine, phenylalanine and valine occurred at $70,80,75$ and 


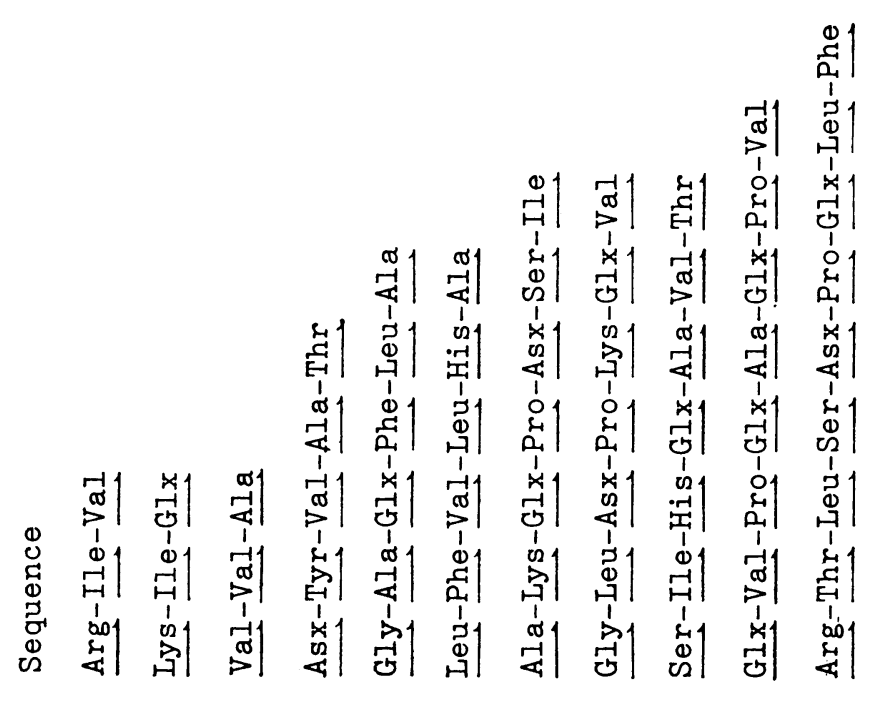

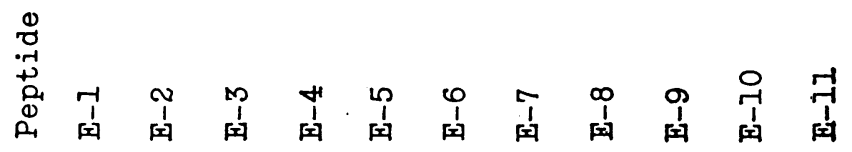




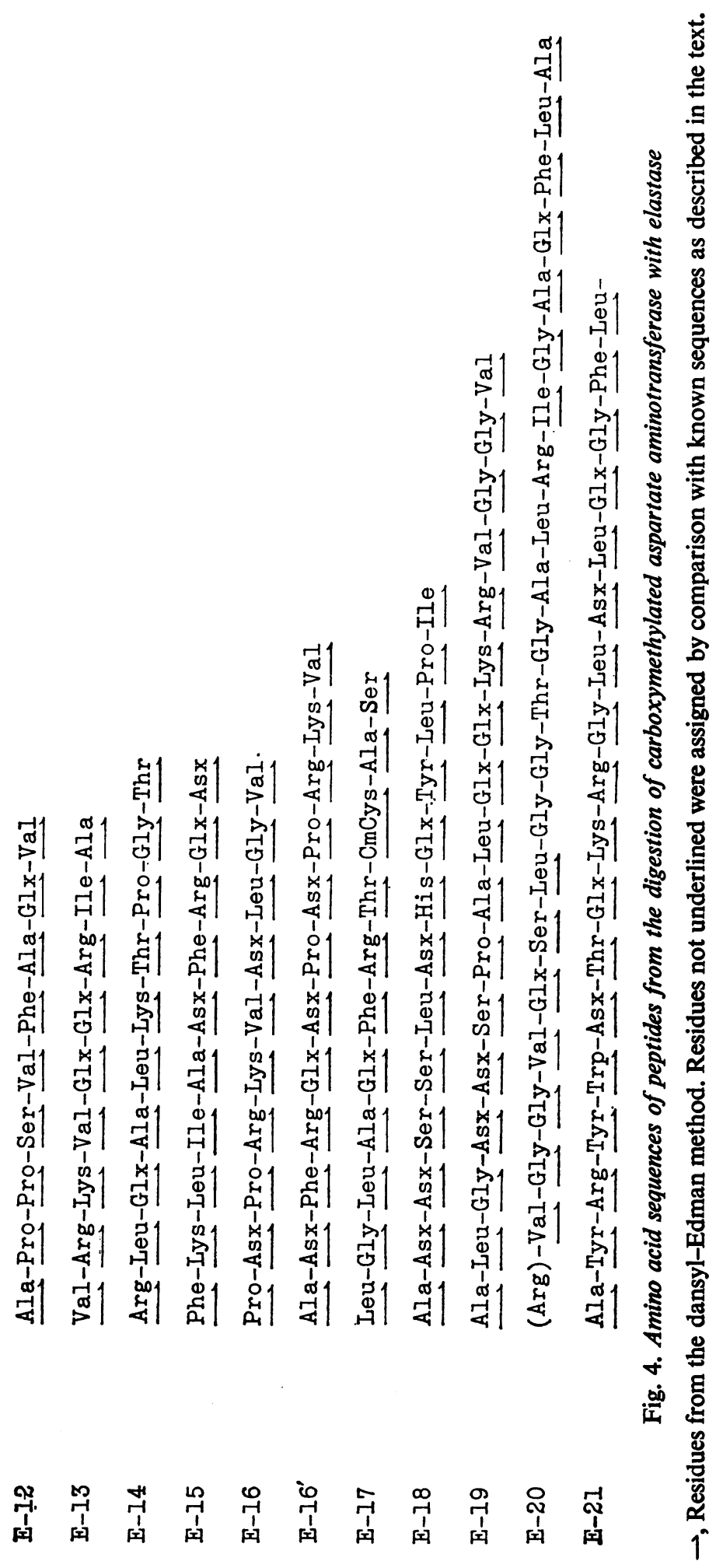

Vol. 133 


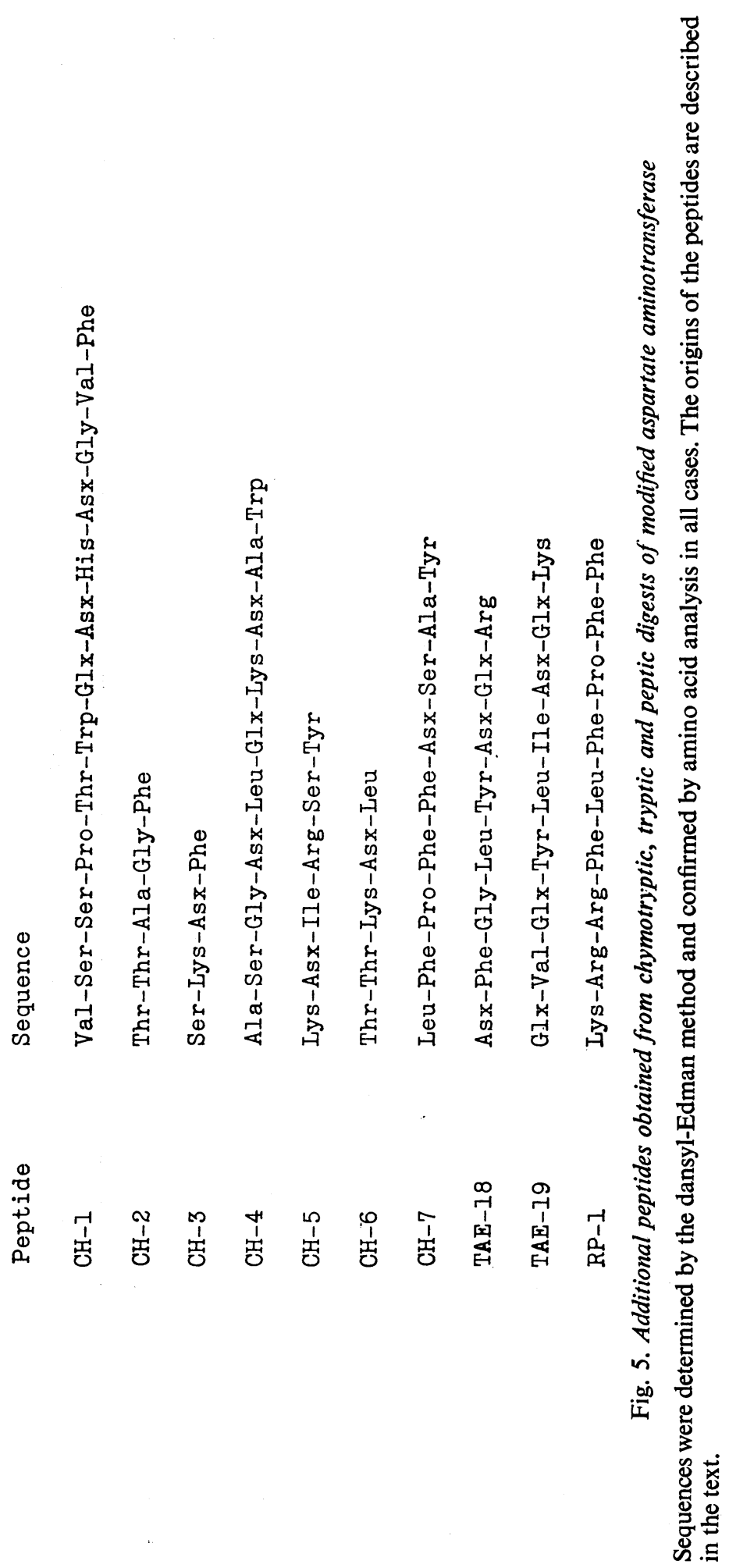




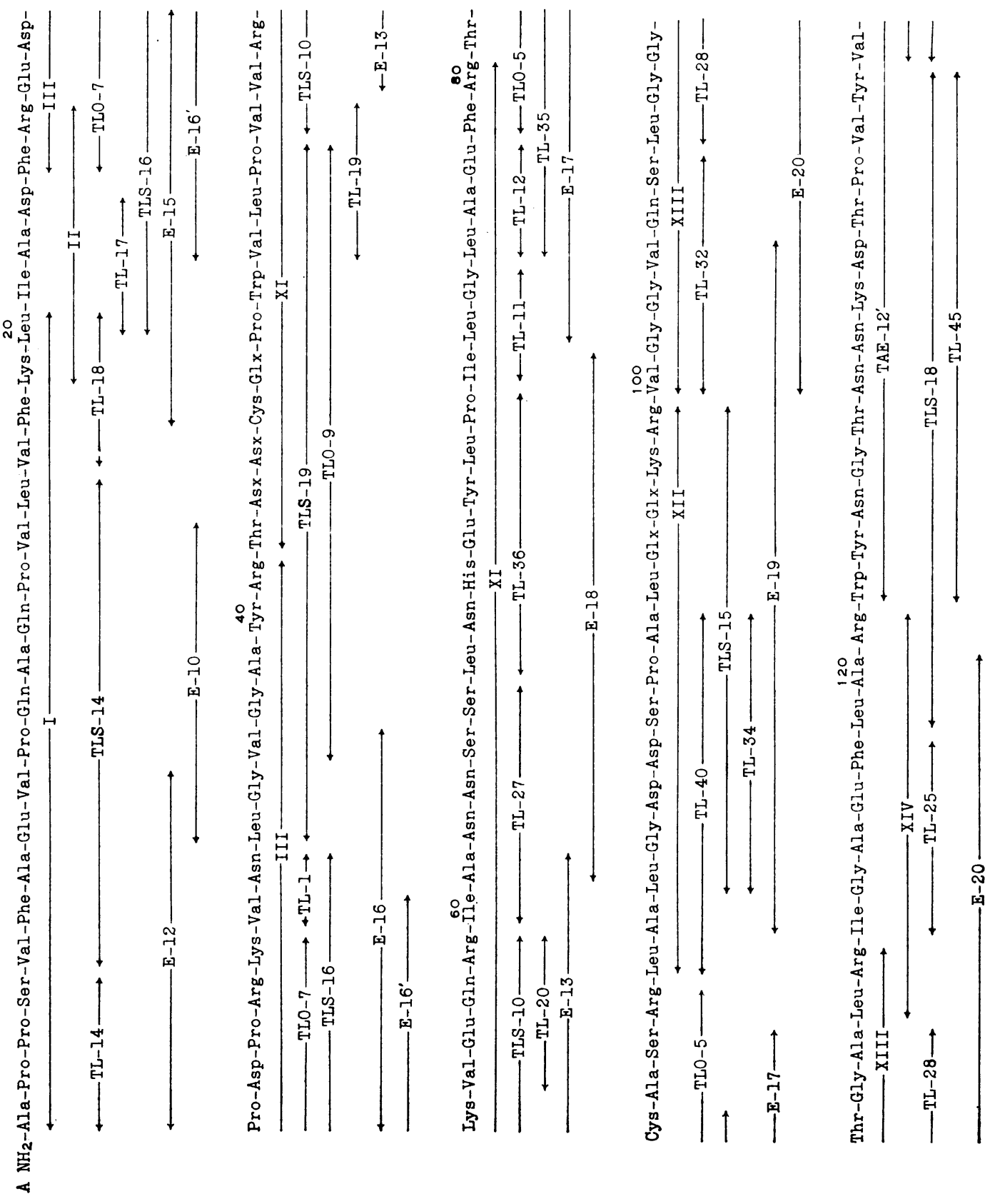




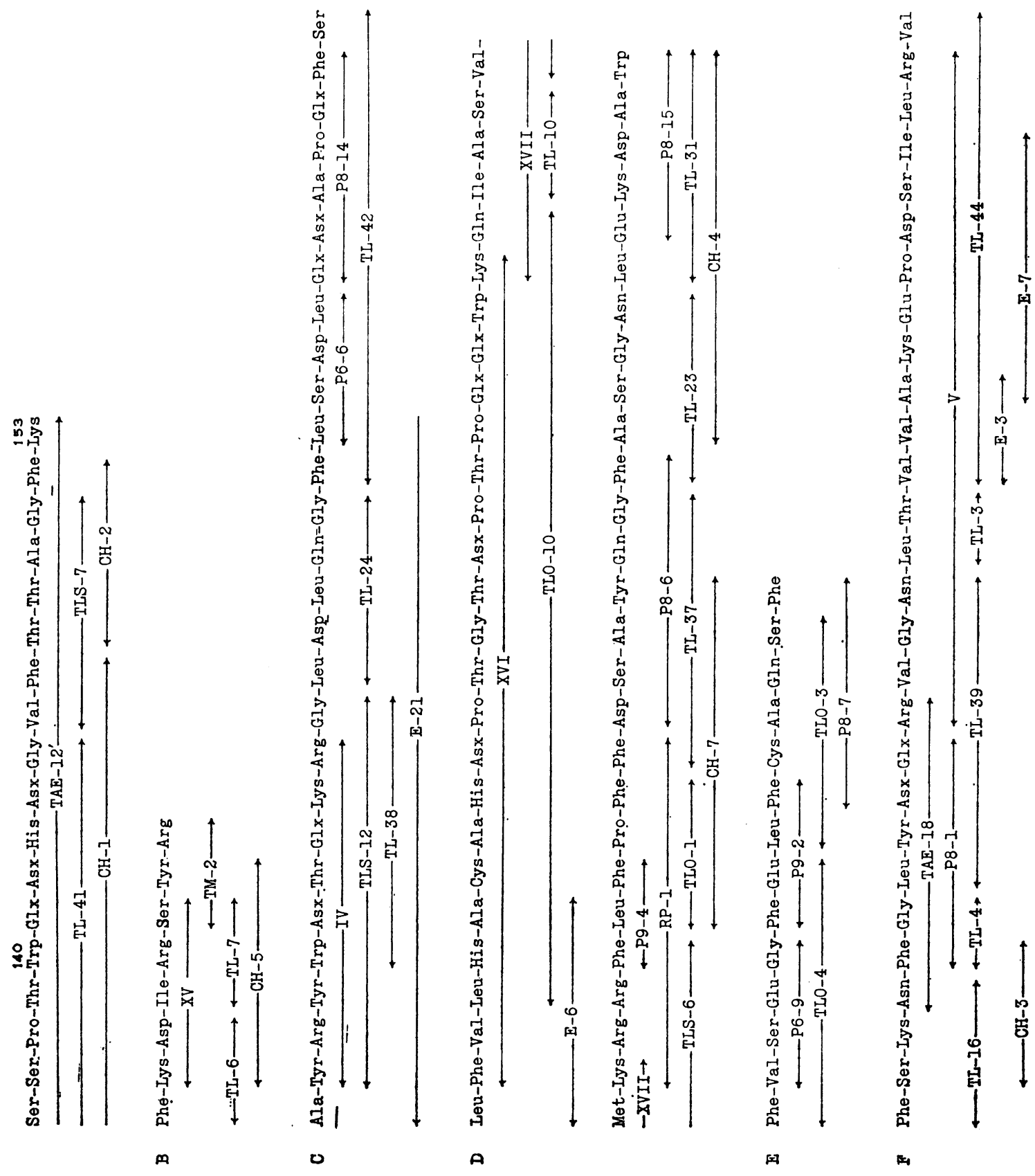



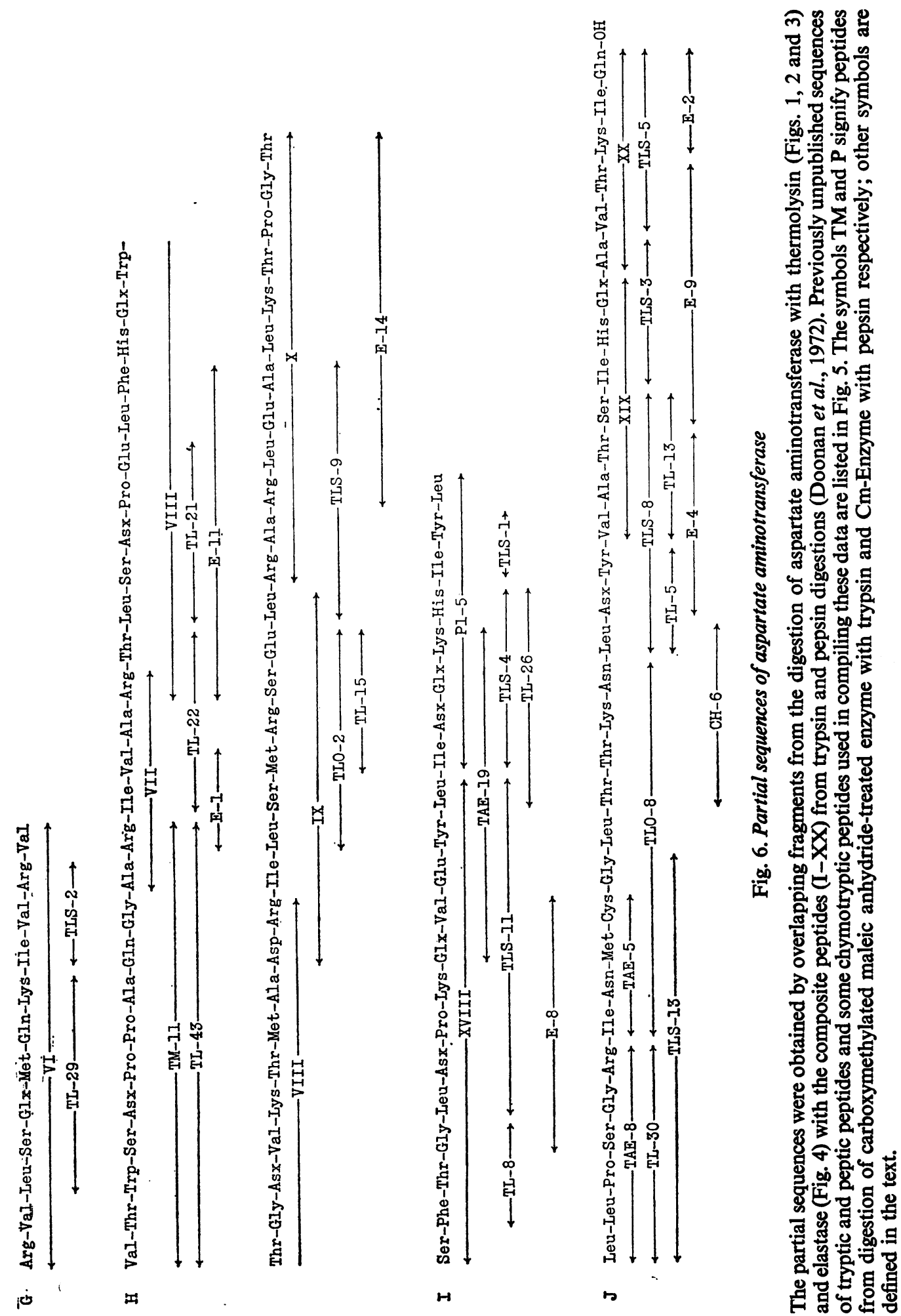

Vol. 133 
$60 \%$ respectively of the available cleavage points. This rather extensive degradation led to a large number of relatively small peptides (average size, five residues). The limited digest with thermolysin (Fig. 3) was performed to obtain larger peptides. We digested the enzyme after it had been oxidized with performic acid to facilitate isolation of peptides containing cysteine residues, since their position in the structure was not well known. Five cysteine residues were located in peptides from the digest and this represents the total cysteine content of the enzyme. It is interesting that two of the peptides from this digest (TLO-9 and TLO-10) contained tryptophan. The state of the residue in peptide TLO-9 is not known, because its position was established by comparison with other known sequences. It appeared, however, that the tryptophan residue in peptide TLO-10 was not modified by the performic acid oxidation; treatment of peptide TLO-10 with a mixture of carboxypeptidases A and B led to the liberation of glutamine, lysine and tryptophan in the molar proportion 1.0:1.0:0.9 (Supplementary Publication SUP 50018). The tryptophan residue was identified by its elution time on amino acid analysis.

Digestion of aspartate aminotransferase with elastase was undertaken to exploit the unusual specificity of this enzyme (Shotton, 1970). The results in Fig. 4 show that elastase cleaved primarily $C$-terminal to valine, threonine and alanine, but cleavage was also observed at leucine, isoleucine, serine and phenylalanine. Thus, although elastase cleaves preferentially at amino acid residues with short side-chains, the specificity is, in fact, rather general. Elastase showed a considerably higher
Table 1. Amino acid composition of cytoplasmic aspartate aminotransferase and of the partial sequences reported here

Values are rounded to the nearest integer. (a) Data from Banks et al. (1968); (b) data from MartinezCarrion et al. (1967). The total value was derived from digests with trypsin, pepsin, thermolysin, elastase and chymotrypsin.

\section{No. of residues}

$\begin{array}{crr}\begin{array}{c}\text { Cytoplasmic enzyme } \\ \text { (based on subunit mol.wt. } 46000)\end{array} & \\ \overbrace{(a)} & \begin{array}{r}\text { Total } \\ \text { value }\end{array} \\ 43 & (b) & 41 \\ 26 & 42 & 24 \\ 27 & 23 & 25 \\ 41 & 25 & 40 \\ 22 & 45 & 21 \\ 27 & 24 & 28 \\ 31 & 28 & 33 \\ 29 & 32 & 30 \\ 5 & 28 & 6 \\ 18 & 6 & 18 \\ 38 & 18 & 40 \\ 12 & 39 & 12 \\ 21 & 12 & 23 \\ 10 & 23 & 9 \\ 20 & 10 & 19 \\ 8 & 19 & 7 \\ 24 & 8 & 25 \\ 5 & 26 & 5 \\ 407 & 5 & 406\end{array}$

Table 2. Amino acid compositions of selected peptides from Figs. 1, 2 and 3

The presence of tryptophan $(+)$ was detected by reaction with the Ehrlich reagent.

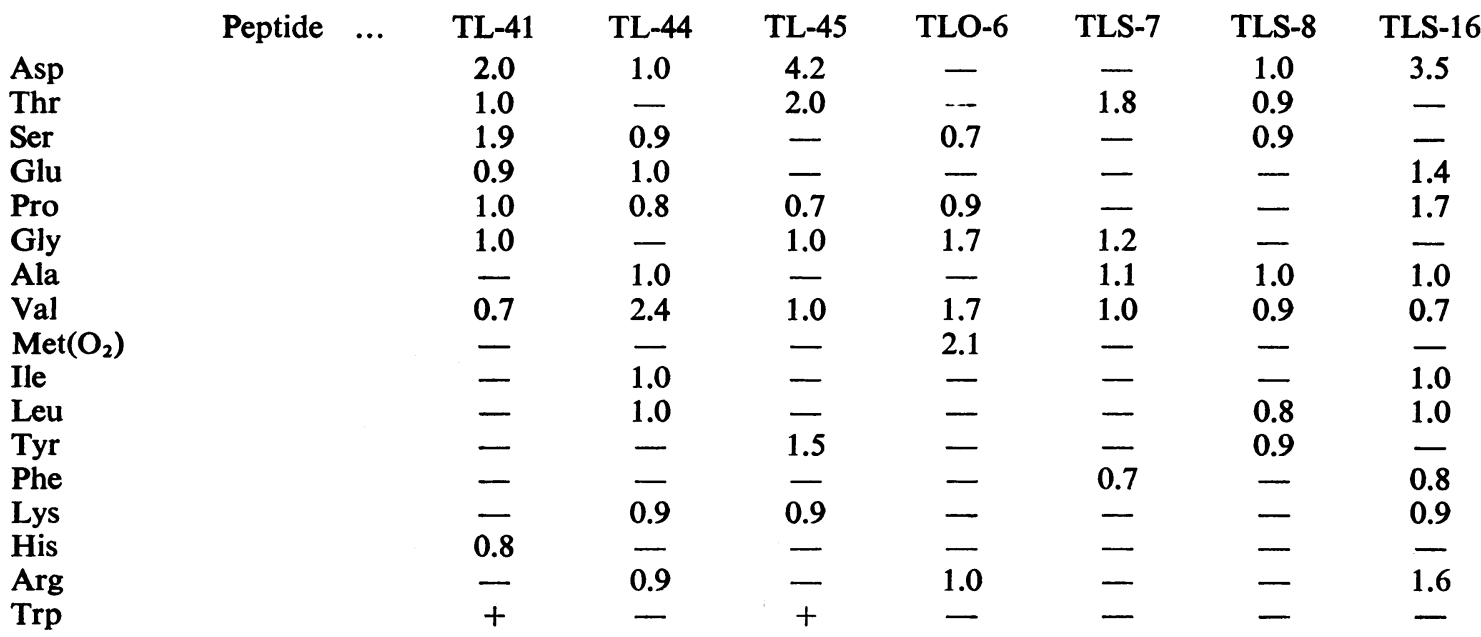


reactivity towards aspartate aminotransferase than did the other proteolytic enzymes used. In a trial digest at the normal substrate-to-enzyme ratio of 100:1 and $37^{\circ} \mathrm{C}$, uptake of aq. $\mathrm{NH}_{3}$ indicated that 50 peptide bonds were cleaved in $10 \mathrm{~min}$. To produce larger fragments, the final substrate-to-enzyme ratio used was 500:1 and digestion was stopped when the equivalent of 40 peptide bonds had been hydrolysed. From this digest, peptides representing only $40 \%$ of the total structure of aspartate aminotransferase were isolated (Fig. 4). The rest of the molecule was in the form of large insoluble fragments that could not be purified from the available material.

We thank Mr. Domenico Dall'Oco for assistance in the purification of peptides and Mr. Antonio Balestrino for preparation of aspartate aminotransferase. Financial support from the Science Research Council (H. J. D., R. H. and J. M. W.) and Roche Products Ltd., is gratefully acknowledged.

\section{References}

Ambler, R. P. (1967) Methods Enzymol. 11, 155-166 Ambler, R. P. (1972) Methods Enzymol. 25, 262-272

Banks, B. E. C., Doonan, S., Lawrence, A. J. \& Vernon, C. A. (1968) Eur. J. Biochem. 5, 528-539
Cole, R. D. (1967) Methods Enzymol. 11, 315-317

Crestfield, A. M., Moore, S. \& Stein, W. H. (1963) J. Biol. Chem. 238, 622-627

Doonan, S., Doonan, H. J., Riva, F., Vernon, C. A., Walker, J. M., Bossa, F., Barra, D., Carloni, M. \& Fasella, P. (1972) Biochem. J. 130, 443-452

Gray, W. R. (1967) Methods Enzymol. 11, 469-475

Hartley, B. S. (1970) Biochem. J. 119, 805-822

Hirs, C. H. W. (1956) J. Biol. Chem. 219, 611-621

Light, A. (1972) Methods Enzymol. 25, 253-262

Martinez-Carrion, M., Turano, C., Chiancone, E., Bossa, F., Giartosio, A., Riva, F. \& Fasella, P. (1967) J. Biol. Chem. 242, 2397-2409

Matsubara, H. (1970) Methods Enzymol. 19, 642-651

Ovchinnikov, Yu. A., Kiryushkin, A. A., Egorov, Ts. A., Abdulaev, N. G., Kiselev, A. P., Modyanov, N. N., Grishin, E. V., Sukhikh, A. P., Vinogradova, E. I., Feigina, M. Yu., Aldanova, N. A., Lipkin, V. M., Braunstein, A. E., Polyanovsky, O. L. \& Nosikov, V. V. (1971) FEBS Lett. 17, 133-136

Ovchinnikov, Yu. A., Egorov, Ts. A., Aldanova, N. A., Feigina, M. Yu., Lipkin, V. M., Abdulaev, N. G., Grishin, E. V., Kiselev, A. P., Modyanov, N. N., Braunstein, A. E., Polyanovsky, O. L. \& Nosikov, V. V. (1973) FEBS Lett. 29, 31-34

Shotton, D. M. (1970) Methods Enzymol. 19, 113140

Waley, S. G. \& Watson, J. (1953) Biochem. J. 55, 328337 